\title{
Left Ventricular Mass Progression despite Stable Blood Pressure and Kidney Function in Stage 3 Chronic Kidney Disease
}

\author{
Michael E. Seifert ${ }^{a, b, e}$ Lisa de las Fuentes ${ }^{c, f} \quad$ Charles Ginsberg $^{f}$ \\ Marcos Rothstein ${ }^{d, f}$ Dennis J. Dietzen ${ }^{e}$ Steven C. Cheng ${ }^{d, f}$ Will Ross ${ }^{d, f}$ \\ David Windus ${ }^{d, f}$ Victor G. Dávila-Román ${ }^{c, f}$ Keith A. Hruskab,e \\ a Division of Pediatric Nephrology, Southern Illinois University, Springfield, III., b Division of Pediatric Nephrology, \\ ${ }^{\mathrm{C} C a r d i o v a s c u l a r}$ Imaging and Clinical Research Core Laboratory, Cardiovascular Division, ${ }^{\mathrm{d}}$ Renal Division, and \\ Departments of ${ }^{e}$ Pediatrics and ${ }^{\mathrm{f}}$ Medicine, Washington University, St. Louis, Mo., USA
}

\section{Key Words}

Cardiovascular biomarkers - Chronic kidney disease .

Ventricular hypertrophy

\section{Abstract}

Background/Aims: Progressive chronic kidney disease (CKD) is associated with worsening cardiovascular (CV) risk not explained by traditional risk factors. Left ventricular (LV) hypertrophy (LVH) is an important CV risk factor, but its progression has not been documented in early CKD. We explored whether progression of LVH in early CKD would occur despite stable kidney function. Methods: We conducted a post hoc analysis of a 12-month study of lanthanum carbonate in stage 3 CKD, which included longitudinal assessments of $\mathrm{CV}$ biomarkers. Primary outcome for the analysis was the change in LV mass (LVM) indexed to height in meters ${ }^{2.7}$ $\left(\mathrm{LVM} / \mathrm{Ht}^{2.7}\right)$. Secondary outcomes were changes in blood pressure (BP), pulse-wave velocity, LV systolic/diastolic function, fibroblast growth factor 23 (FGF23), klotho, and estimated glomerular filtration rate (eGFR). Results: Thirty-one of 38 original subjects had sufficient data for analysis. LVM/ $\mathrm{Ht}^{2.7}$ increased ( $47 \pm 13$ vs. $53 \pm 13 \mathrm{~g} / \mathrm{m}^{2.7}, \mathrm{p}=0.006$ ) over 12 months despite stable BP, stable eGFR and normal LV systolic function. Vascular stiffness and LV diastolic dysfunction persisted throughout the study. Klotho levels decreased ( $748 \pm 289$ to $536 \pm 410 \mathrm{pg} / \mathrm{ml}, \mathrm{p}=0.03$ ) but were unrelated to changes in $\mathrm{LVM} / \mathrm{Ht}^{2.7}$. The change in FGF23/klotho ratio was strongly correlated with changes in $\mathrm{LVM} / \mathrm{Ht}^{2.7}\left(\mathrm{r}^{2}=0.582\right.$, $p=0.03)$. Conclusion: Subjects with stage 3 CKD exhibited increasing LVM, persistent LV diastolic dysfunction and vascular stiffness despite stable kidney function, BP and LV systolic function. Abnormal FGF23 signaling due to reduced klotho expression may be associated with increasing LVM. These findings deserve further evaluation in a larger population given the adverse prognostic value of these CV biomarkers.

(c) 2014 S. Karger AG, Basel

\section{Introduction}

Chronic kidney disease (CKD) is associated with increased cardiovascular (CV) risk compared with the general population [1-3]. Traditional CV risk factors such as age, sex, smoking, hypertension, cholesterol, and diabetes

\section{KARGER}

E-Mail karger@karger.com

www.karger.com/ajn
C 2014 S. Karger AG, Basel

$0250-8095 / 14 / 0395-0392 \$ 39.50 / 0$
Keith A. Hruska, MD

Division of Pediatric Nephrology, Department of Pediatrics, Washington University 660 S. Euclid Ave., Campus Box 8208

St. Louis, MO 63110 (USA)

E-Mail hruska_k@kids.wustl.edu 
do not account for the increased risk in the CKD population [4]. CV risk consists of fatal and nonfatal myocardial infarction, congestive heart failure, arrhythmias and sudden death. Biomarkers associated with $\mathrm{CV}$ risk include left ventricular (LV) mass (LVM), carotid-femoral pulse-wave velocity (PWV), LV systolic and LV diastolic function, and vascular calcification. Circulating biomarkers are also abnormal in CKD, worsen with progressive $\mathrm{CKD}$, and illustrate an inverse correlation between glomerular filtration rate (GFR) and CV risk [3].

Although an estimated $10 \%$ of the general population has stage $3 \mathrm{CKD}$ with an estimated GFR (eGFR) between 30 and $59 \mathrm{ml} / \mathrm{min} / 1.73 \mathrm{~m}^{2}$ [5], most of these individuals do not progress to end-stage kidney disease (ESKD). Moreover, patients that do progress to ESKD may do so with a variable rate of decline over a period of several months or years. Conceivably, many patients will maintain stable eGFR and remain at the same stage of CKD for years. Despite the apparent stability of kidney function, there is ongoing exposure to the pathophysiology of mild to moderate CKD, such as release of substances from the diseased kidney, hypertension, hyperphosphatemia, and vasoactive and hypertrophic signaling from the renin-angiotensin-aldosterone axis. While there are numerous longitudinal studies examining progression of biomarkers of CV risk in stage $5 \mathrm{CKD}$ [6-11], there are few longitudinal studies in patients with stable mild to moderate CKD. Studies in mild to moderate CKD often use progression of $\mathrm{CKD}$ as an outcome measure, rather than examine those with stable CKD in a longitudinal fashion to determine changes in biomarkers associated with CV risk [12-16].

Recently, we published a randomized, double-blind, placebo-controlled pilot and feasibility study of the phosphorus binder lanthanum carbonate $\left(\mathrm{LaCO}_{3}\right)$ in 38 patients with stage $3 \mathrm{CKD}$ [17]. Phosphorus binder therapy did not significantly affect phosphate homeostasis or biomarkers of CV risk after 12 months, but we noted a similar trend for increased $\mathrm{LVM} / \mathrm{Ht}^{2.7}$ within the $\mathrm{LaCO}_{3}$ and placebo groups that did not reach statistical significance. Since the cohort was not significantly affected by the intervention compared to placebo, we combined the two groups for a longitudinal post hoc analysis of $\mathrm{LVM} / \mathrm{Ht}^{2.7}$ in stable stage $3 \mathrm{CKD}$.

\section{Subjects and Methods}

\section{Subjects}

The original study protocol and post hoc analysis were both approved by the Human Research Protection Office at Washington University in St. Louis. Inclusion criteria, exclusion criteria and methods for stratification and randomization were published previously. Specifically relevant to the post hoc analysis, a history of prior or current congestive heart failure and severe hypertension were each exclusion criteria in the original study [17]. Briefly, 38 subjects with stage $3 \mathrm{CKD}$ were stratified for age, gender, race and diabetes status, and then randomized into 2 groups allocated 1:1 to receive either $\mathrm{LaCO}_{3}$ or a matching placebo with meals 3 times daily for 12 months. The primary end point of the original study was the change in serum phosphorus. Secondary end points included the change in mean carotid-femoral PWV, 24-hour urine phosphorus, tubular reabsorption of phosphorus, vascular calcification score, carotid artery intima-media thickness, $\mathrm{LVM} / \mathrm{Ht}^{2.7}$, LV ejection fraction (LVEF), plasma fibroblast growth factor 23 (FGF23), plasma Dickkopf-related protein 1 (DKK1) and plasma sclerostin. $\mathrm{LaCO}_{3}$ and placebo groups were analyzed as a single cohort in this post hoc analysis since no differences in outcomes were detected during the original study.

\section{Evaluations}

$\mathrm{CV}$ assessments were performed at baseline and 12 months. PWV was determined by use of applanation tonometry of the carotid and femoral arteries (SphygmoCor, AtCor Medical, Australia) as previously described and validated [17-22]. The applanation tonometry measurements were performed by a research technician who was blinded to clinical data, echocardiographic results and treatment group. Vascular stiffness was defined as a mean PWV greater than the 50th percentile for age $(9.8 \mathrm{~m} / \mathrm{s})$ using data from The Reference Values for Arterial Stiffness' Collaboration [23].

Two-dimensional (2D) and M-mode echocardiograms were performed as described previously [17]. LVEF was determined by 2D echocardiography using the modified Simpson's method of disks; LVM was measured by the 2D-guided M-mode-derived cubed method and indexed to both body surface area (LVM/BSA) and height in meters raised to the power of $2.7\left(\mathrm{LVM} / \mathrm{Ht}^{2.7}\right)$ [24]. Although LVM/BSA is commonly used in clinical trials, it underestimates the degree of LV hypertrophy (LVH) in overweight and obese individuals. $\mathrm{LVM} / \mathrm{Ht}^{2.7}$ enhances the ability to detect $\mathrm{LVH}$ in this setting [24-26]. Subjects were considered to have LVH if the $\mathrm{LVM} / \mathrm{Ht}^{2.7}$ was $>51 \mathrm{~g} / \mathrm{m}^{2.7}$ [24]. Diastolic function metrics were obtained using pulsed-wave Doppler and included early peak mitral inflow velocity $(\mathrm{E})$, late peak mitral inflow velocity $(\mathrm{A})$, the E/A ratio, and left atrial volume (LAV) [24, 27]. Additional diastolic function metrics were obtained using pulsed-wave tissue Doppler imaging and included early diastolic lateral annular velocity (lateral $\mathrm{e}^{\prime}$ ) and the ratio of $\mathrm{E}$ to lateral $\mathrm{e}^{\prime}$ (lateral $\mathrm{E} / \mathrm{e}^{\prime}$ ratio), which provides an estimate of left atrial pressure (LAP) [27]. Normal reference values for these metrics are as follows: $\mathrm{LAV}<34 \mathrm{ml} / \mathrm{m}^{2}$, lateral $\mathrm{e}^{\prime} \geq 10 \mathrm{~cm} / \mathrm{s}$, lateral E/e' ratio $\leq 8$ (also normal between $9-12$ if normal LAV), E/A ratio 1-2 (along with normal LAV and normal lateral e') [24, 27]. Subjects were considered to have diastolic dysfunction if either of the following patterns were detected by echocardiography: (1) impaired myocardial relaxation: $\mathrm{E} / \mathrm{A}<0.8$, lateral $\mathrm{e}^{\prime}<10 \mathrm{~cm} / \mathrm{s}$, lateral $\mathrm{E} / \mathrm{e}^{\prime}<8, \mathrm{LAV}>34 \mathrm{ml} / \mathrm{m}^{2}$, and/or (2) increased LAP: lateral E/e $>12$ with LAV $>34 \mathrm{ml} / \mathrm{m}^{2}$. The classification scheme for diastolic dysfunction was drawn from a recently published guideline by the American Society of Echocardiography [27]. All measurements were performed in accordance to published guidelines and represent the average of three consecutive cardiac cycles obtained by a single observer blinded to all clinical parameters and treatment group. 
Plasma FGF23 and Soluble Klotho Levels

Blood samples were obtained from each subject at the baseline visit and after 12 months of treatment. Plasma levels of FGF23 were measured in duplicate using a commercially available ELISA kit as previously described [17]. Soluble klotho levels were measured in duplicate using a commercially available ELISA kit according to the manufacturer's instructions (Immuno-Biological Laboratories, Japan).

\section{Outcome Definitions}

The primary outcome was the change in LVM/ $\mathrm{Ht}^{2.7}\left(\mathrm{~g} / \mathrm{m}^{2.7}\right)$ from baseline to month 12 . Secondary outcomes included changes in the nonindexed LVM (g) and LVM indexed to BSA [LVM/BSA $\left.\left(\mathrm{g} / \mathrm{m}^{2}\right)\right]$, systolic blood pressure (SBP), diastolic blood pressure (DBP), carotid-femoral PWV, LVEF, E velocity, A velocity, E/A ratio, lateral $\mathrm{e}^{\prime}$ velocity, lateral $\mathrm{E} / \mathrm{e}^{\prime}$ ratio, plasma $\mathrm{FGF} 23$, plasma soluble klotho, FGF23/klotho ratio and eGFR (calculated using the Modification of Diet in Renal Disease Study Equation) [28] from baseline to month 12 .

\section{Statistical Analysis}

Statistical analysis was performed by a statistician who remained blinded to the identity of the subjects and their original study groups (J.M.). The data were analyzed using the software package SAS 9.1 (Cary, N.C., USA). All outcomes were analyzed in both original treatment arms combined since there were no significant differences between groups in the original study [17]. The distribution of each outcome variable was evaluated for normality using Kolmogorov-Smirnov Z test. Signed-rank test (non-normally distributed data) and paired test (normally distributed data) were used to test differences of continuous variables from baseline to the 12 -month visit. Bivariate correlations involving normally distributed variables were performed using Pearson's correlation. Independent categorical variables were compared using the $\chi^{2}$ test; paired categorical variables were compared using McNemar's test. Normally distributed data are presented as mean \pm standard deviation. Non-normally distributed data are presented as median (range). All tests were two tailed; statistical significance was considered at $\mathrm{p}<0.05$.

\section{Results}

\section{Baseline Demographics}

Of the 38 subjects from the original cohort, 31 had complete demographic, biochemical, and CV data at the baseline and 12-month visit and were included in the post hoc analysis. Subjects were excluded from the analysis due to either inadequate plasma remaining for measuring circulating klotho levels or incomplete data for assessment of diastolic function, which were both outcomes not analyzed in the original study. There were no significant differences in baseline demographic or clinical data in included versus excluded subjects (data not shown). The demographic data for the combined cohort are presented in table 1. At baseline, LVH was present in 10/31 (32\%)
Table 1. Baseline demographic data for all 31 subjects included in the post hoc analysis

\begin{tabular}{lc}
\hline Age, years & $62 \pm 12$ \\
Height, cm & $174 \pm 11$ \\
Weight, kg & $96 \pm 22$ \\
BMI & $31 \pm 5$ \\
SBP, mm Hg & $131 \pm 14$ \\
DBP, mm Hg & $77 \pm 10$ \\
Heart rate, beats per min & $71 \pm 10$ \\
LaCO $_{3}$ placebo treatment group & $16 / 15$ \\
Males/females & $21 / 10$ \\
Diabetes mellitus & $11(36)$ \\
Race & \\
$\quad$ African-American & $8(26)$ \\
Caucasian & $21(68)$ \\
Other & $2(6)$ \\
Antihypertensive use & $25(80)$ \\
\hline
\end{tabular}

Data are presented as mean \pm standard deviation or number (\%).

and diastolic dysfunction was present in 15/31 (48\%, all with impaired myocardial relaxation: 13 had normal LAP and 2 had increased LAP; table 2).

\section{Primary Outcome of the Combined Cohort Analysis}

Mean LVM/ $\mathrm{Ht}^{2.7}$ significantly increased from $47.4 \pm$ $13.2 \mathrm{~g} / \mathrm{m}^{2.7}$ at baseline to $53.4 \pm 12.9 \mathrm{~g} / \mathrm{m}^{2.7}$ at 12 months $(\mathrm{p}=0.006$; table 2 , fig. 1$)$. The proportion of subjects with LVH increased from $32 \%$ at baseline to $48 \%$ at 12 months, but this change was not statistically significant (table 2). Of the subjects without LVH at baseline, 29\% developed $\mathrm{LVH}$ at 12 months; in contrast, only one subject with $\mathrm{LVH}$ at baseline demonstrated normal $\mathrm{LVM} / \mathrm{Ht}^{2.7}$ at 12 months. The change in $\mathrm{LVM} / \mathrm{Ht}^{2.7}$ from baseline to the 12 -month visit was similar within the original study groups $\left(\mathrm{LaCO}_{3}: 45.6 \pm 13.4\right.$ to $53.2 \pm 13.3 \mathrm{~g} / \mathrm{m}^{2.7}, \mathrm{p}=0.44$; placebo: $49.3 \pm 13.2$ to $\left.53.6 \pm 13.0 \mathrm{~g} / \mathrm{m}^{2.7}, \mathrm{p}=0.51\right)$. The between-group comparison of the change in $\mathrm{LVM} / \mathrm{Ht}^{2.7}$ was not statistically significant $(\mathrm{p}=0.36)$. Mean eGFR was $46 \mathrm{ml} / \mathrm{min} / 1.73 \mathrm{~m}^{2}$ at baseline and did not significantly change during the study, demonstrating stability of stage $3 \mathrm{CKD}$ during the follow-up period (table 2).

\section{Secondary Outcomes in the Combined Cohort \\ Analysis}

Mean nonindexed LVM significantly increased from $203 \pm 79 \mathrm{~g}$ at baseline to $223 \pm 70 \mathrm{~g}$ at 12 months $(\mathrm{p}=0.02$; table 2). Mean LVM/BSA also significantly increased from $100 \pm 29 \mathrm{~g} / \mathrm{m}^{2}$ at baseline to $106 \pm 27 \mathrm{~g} / \mathrm{m}^{2}$ at 12 
Table 2. Comparison of clinical data at baseline and 12-month visit for all 31 subjects included in the post hoc analysis

\begin{tabular}{|c|c|c|c|}
\hline & $\begin{array}{l}\text { Baseline } \\
(\mathrm{n}=31)\end{array}$ & $\begin{array}{l}12 \text { months } \\
(\mathrm{n}=31)\end{array}$ & $\mathrm{p}$ \\
\hline \multicolumn{4}{|l|}{ Biochemical data } \\
\hline BMI & $31 \pm 5$ & $32 \pm 6$ & 0.16 \\
\hline Serum creatinine, $\mathrm{mg} / \mathrm{dl}$ & $1.7 \pm 0.3$ & $1.7 \pm 0.4$ & 0.80 \\
\hline $\mathrm{eGFR}, \mathrm{ml} / \mathrm{min} / 1.73 \mathrm{~m}^{2}$ & $46 \pm 12$ & $47 \pm 15$ & 0.95 \\
\hline Serum calcium, mg/dl & $9.2 \pm 0.3$ & $9.5 \pm 0.4$ & 0.70 \\
\hline Serum phosphorus, mg/dl & $3.4 \pm 0.5$ & $3.2 \pm 0.5$ & 0.80 \\
\hline TRP, $\%$ & $77 \pm 10$ & $73 \pm 10$ & 0.45 \\
\hline Intact $\mathrm{PTH}, \mathrm{pg} / \mathrm{ml}$ & $67 \pm 50$ & $71 \pm 48$ & 0.52 \\
\hline FGF23, pg/ml & $58(24-201)$ & $55(33-367)$ & 0.95 \\
\hline Soluble klotho, pg/ml & $748 \pm 289$ & $536 \pm 410$ & $0.03^{\mathrm{a}}$ \\
\hline FGF23/klotho ratio & $0.09 \pm 0.07$ & $0.26 \pm 0.25$ & $0.01^{\mathrm{a}}$ \\
\hline \multicolumn{4}{|l|}{ Cardiovascular data } \\
\hline $\mathrm{SBP}, \mathrm{mm} \mathrm{Hg}$ & $131 \pm 14$ & $130 \pm 12$ & 0.69 \\
\hline $\mathrm{DBP}, \mathrm{mm} \mathrm{Hg}$ & $77 \pm 10$ & $71 \pm 8$ & $0.01^{\mathrm{a}}$ \\
\hline Heart rate, beats per min & $70 \pm 10$ & $69 \pm 10$ & 0.25 \\
\hline LVM, g & $203 \pm 79$ & $223 \pm 70$ & $0.02^{\mathrm{a}}$ \\
\hline LVM, $\mathrm{g} / \mathrm{m}^{2}$ & $100 \pm 29$ & $106 \pm 27$ & $0.03^{\mathrm{a}}$ \\
\hline $\mathrm{LVM}, \mathrm{g} / \mathrm{m}^{2.7}$ & $47 \pm 13$ & $53 \pm 13$ & $0.006^{\mathrm{a}}$ \\
\hline $\mathrm{LVH}$ & $10(32)$ & $15(48)$ & 0.33 \\
\hline LVEF, \% & $62 \pm 10$ & $66 \pm 9$ & $0.04^{\mathrm{a}}$ \\
\hline $\mathrm{PWV}, \mathrm{m} / \mathrm{s}$ & $10.7 \pm 1.8$ & $10.1 \pm 2.1$ & 0.08 \\
\hline \multicolumn{4}{|l|}{ Diastolic function } \\
\hline E velocity, $\mathrm{cm} / \mathrm{s}$ & $\begin{array}{l}0.57 \\
(0.33-1.23)\end{array}$ & $\begin{array}{l}0.58 \\
(0.34-1.38)\end{array}$ & 0.74 \\
\hline A velocity, $\mathrm{cm} / \mathrm{s}$ & $\begin{array}{l}0.71 \\
(0.47-1.24)\end{array}$ & $\begin{array}{l}0.69 \\
(0.50-1.12)\end{array}$ & 0.25 \\
\hline $\mathrm{E} / \mathrm{A}$ ratio & $\begin{array}{l}0.78 \\
(0.43-1.50)\end{array}$ & $\begin{array}{l}0.80 \\
(0.52-1.75)\end{array}$ & 0.60 \\
\hline Lateral $\mathrm{e}^{\prime}, \mathrm{cm} / \mathrm{s}$ & $8(5-18)$ & $10(5-16)$ & 0.10 \\
\hline Lateral E/e' ratio & $6.3(3.3-22.8)$ & $6.2(3.4-23.6)$ & 0.10 \\
\hline Left atrial volume, $\mathrm{ml} / \mathrm{m}^{2}$ & $51(21-128)$ & $53(26-118)$ & 0.40 \\
\hline Diastolic dysfunction & $15(48)$ & $14(45)$ & 1.00 \\
\hline
\end{tabular}

Data are presented as mean \pm standard deviation, median (range), or number (\%). See the 'Methods' section for normal reference values for the cardiovascular data and diastolic function variables. FGF23 is the only non-normally distributed biochemical variable and is presented as median (range). TRP = Tubular reabsorption of phosphorus; PTH = parathyroid hormone.

a Statistically significant difference in means between the baseline and 12-month visit using paired t test.

months $(\mathrm{p}=0.03$; table 2$)$. SBP remained stable during the study, but a small yet statistically significant decrease in DBP occurred over 12 months (table 2). We observed increased PWV, reflecting vascular stiffness at the baseline visit and at 12 months (table 2), with mean PWV greater than the 50th percentile for age $(9.8 \mathrm{~m} / \mathrm{s})$ using data from The Reference Values for Arterial Stiffness'

LV Mass Progression in Stable Stage 3 CKD

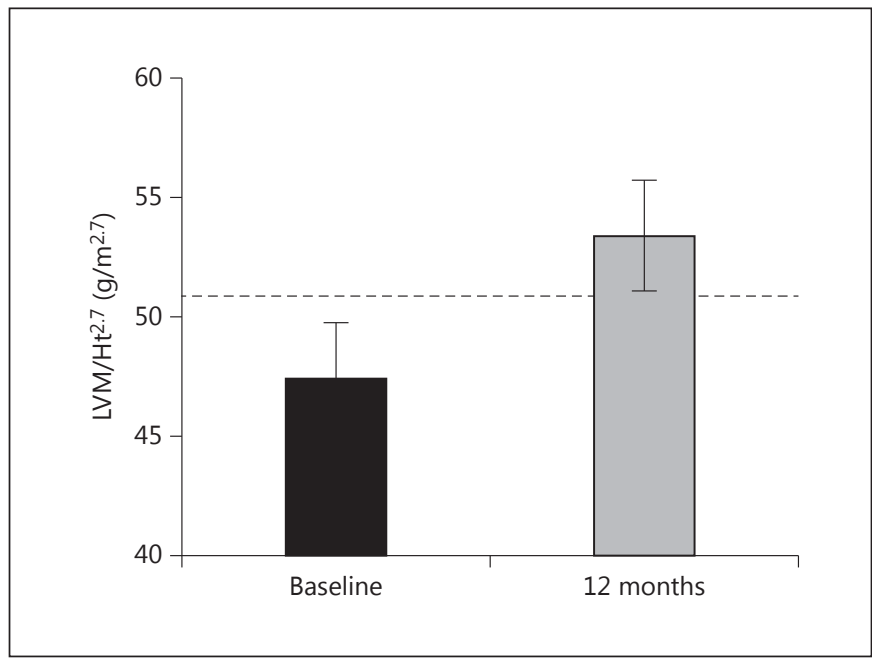

Fig. 1. Comparison of mean $\mathrm{LVM} / \mathrm{Ht}^{2.7}$ between the baseline and 12 -month visit using paired t test. Whiskers represent one standard error of the mean for each group. The dotted line represents the threshold value for diagnosing LVH $\left(51 \mathrm{~g} / \mathrm{m}^{2.7} ; \mathrm{p}=0.006\right)$.

Collaboration [23]. LVEF remained normal at $>60 \%$ throughout the study, with a small but statistically significant increase from baseline to the 12-month visit (table 2).

Diastolic dysfunction was present at baseline and persisted over 12 months in many subjects, although there were no significant changes during the study (table 2). Specifically, the E velocity (median: $0.57-0.58 \mathrm{~cm} / \mathrm{s}$ ), A velocity (median: $0.69-0.71 \mathrm{~cm} / \mathrm{s}$ ), E/A ratio (median: $0.78-0.80$ ), lateral $\mathrm{e}^{\prime}$ (median: $8-10 \mathrm{~cm} / \mathrm{s}$ ), lateral E/e' $\mathrm{ra}-$ tio (median: 6.2-6.3), and LAV (median: $51-53 \mathrm{ml} / \mathrm{m}^{2}$ ) remained unchanged, all consistent with mild diastolic dysfunction [27] (table 2).

Plasma FGF23 levels were variable at the baseline visit and did not change significantly during the study (table 2). Furthermore, the change in FGF23 was not associated with the change in $\mathrm{LVM} / \mathrm{Ht}^{2.7}$ over 12 months (Pearson's $\mathrm{r}^{2}=-0.02, \mathrm{p}=0.92$; fig. 2 ). Mean circulating klotho levels were significantly lower at 12 months versus baseline ( $536 \pm 410$ vs. $748 \pm 289 \mathrm{pg} / \mathrm{ml}$, respectively, $\mathrm{p}=0.03$; table 2 ) and overall were $20-50 \%$ lower than in previous reports using the same ELISA in patients with stage 3 CKD [29]. There was no correlation between change in soluble klotho levels and change in eGFR or LVM/ $\mathrm{Ht}^{2.7}$ over 12 months (data not shown). FGF23 and klotho levels were not correlated with one another at baseline (Pearson's $\mathrm{r}^{2}=-0.124, \mathrm{p}=0.67$ ) but were strongly correlated at 12 months (Pearson's $\mathrm{r}^{2}=0.553, \mathrm{p}=0.04$ ). The FGF23/ 


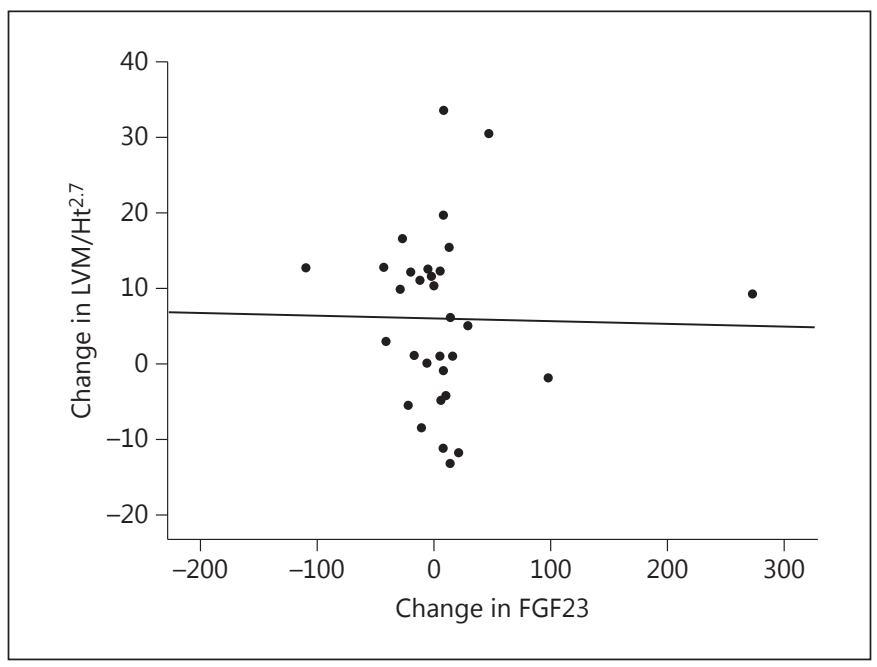

Fig. 2. Scatter plot of the change in FGF23 levels vs. the change in $\mathrm{LVM} / \mathrm{Ht}^{2.7}$ between the baseline and 12 -month visit. The strength $\left(r^{2}=-0.02\right)$ and significance $(p=0.92)$ of the association were generated using Pearson's correlation.

klotho ratio increased significantly over 12 months (0.09 \pm 0.07 to $0.26 \pm 0.25, \mathrm{p}=0.01$; table 2 ). Of the secondary outcomes, only the change in FGF23/klotho ratio was significantly associated with the change in $\mathrm{LVM} / \mathrm{Ht}^{2.7}$ over 12 months (Pearson's $\mathrm{r}^{2}=0.582, \mathrm{p}=0.03$; fig. 3 ).

\section{Discussion}

In this post hoc analysis, we identified a significant increase in $\mathrm{LVM} / \mathrm{Ht}^{2.7}$ over a 12 -month follow-up period in 31 adults with stage $3 \mathrm{CKD}$, despite stable $\mathrm{BP}$, stable kidney function and normal LV systolic function. This increase remained significant across other definitions of LVM, including nonindexed LVM (g) and LVM indexed to BSA $\left(\mathrm{g} / \mathrm{m}^{2}\right)$. Given that approximately $10 \%$ of the general population has stage $3 \mathrm{CKD}$, there is a pressing need to identify biomarkers associated with poor CV outcomes. While it has been previously shown that biomarkers of CV risk (such as LVM) progressively worsen in patients with stage $5 \mathrm{CKD}$ on dialysis, to our knowledge this is the first study to demonstrate progression of LVM (a biomarker that portends adverse CV risk) in an otherwise stable stage 3 CKD population.

We compared our findings with those of a recent study published by Chue et al. [29] that followed 109 subjects with stage $3 \mathrm{CKD}$ in a 40 -week placebo-controlled study using sevelamer carbonate. In their study, LVM (nonin-

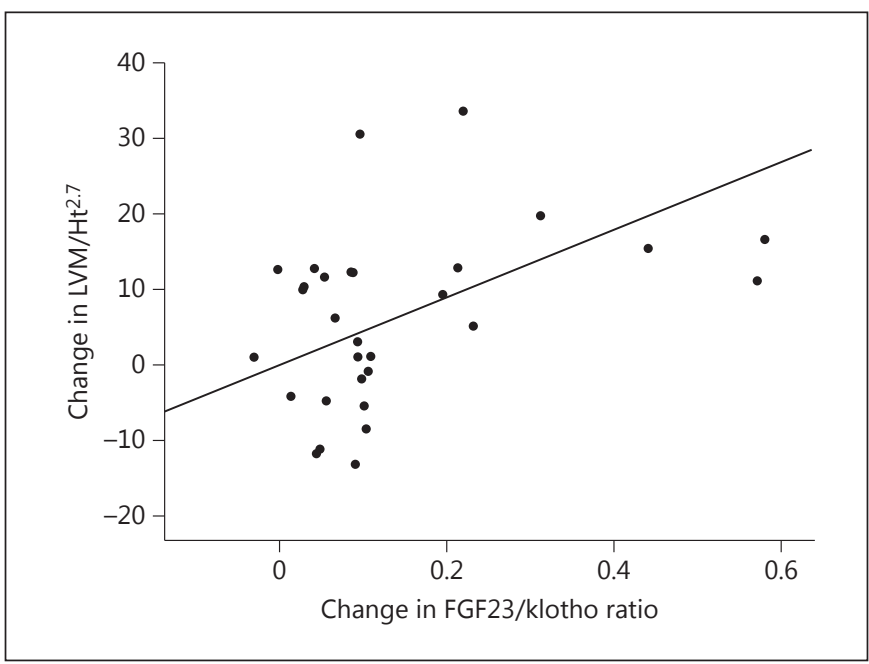

Fig. 3. Scatter plot of the change in FGF23/klotho ratio vs. the change in $\mathrm{LVM} / \mathrm{Ht}^{2.7}$ between the baseline and 12-month visit. The strength $\left(\mathrm{r}^{2}=0.582\right)$ and significance $(\mathrm{p}=0.03)$ of the association were generated using Pearson's correlation.

dexed and indexed to BSA) did not significantly increase in the sevelamer or placebo group over 40 weeks. An important difference between our study and that of Chue et al. [29] is their use of cardiac MRI rather than echocardiography to measure LVM, which precludes a direct comparison of primary outcomes between our two studies. Our two cohorts were similar in age, gender and eGFR, although our cohort had more vascular stiffness, more diastolic dysfunction, and a slightly longer followup period (52 vs. 40 weeks). Importantly, our cohort had lower baseline levels of circulating klotho that declined significantly over 12 months, versus higher baseline klotho levels that remained stable in Chue et al. [29] (using an identical ELISA kit). The decline in klotho levels in our cohort may reflect a decrease in true GFR and subclinical progression of CKD during the study that was not detected using the Modification of Diet in Renal Diseasederived eGFR, as suggested by recent studies of klotho levels as a highly sensitive biomarker of kidney injury in early CKD [30-33].

Although we detected a significant increase in LVM, this was not associated with changes in other biomarkers that have been associated with worsening CV risk such as SBP, DBP, LV systolic function, LV diastolic function, or PWV. However, it is feasible that persistently elevated PWV, a biomarker of vascular stiffness, contributed to cardiac remodeling and increasing LVM as was seen in the Multiethnic Study of Atherosclerosis [34]. Moreover, 
we observed persistent, mild diastolic dysfunction over 12 months in stage $3 \mathrm{CKD}$, which has been previously reported as a correlate of increasing LVM and a strong predictor of mortality in stage 4-5 CKD $[35,36]$.

To our surprise and in contrast to recent animal and human studies, we did not find an association between plasma FGF23 levels and the change in LVM/ $\mathrm{Ht}^{2.7}[37$, 38]. However, we demonstrated a significant decline in circulating klotho levels over 12 months that was not associated with a change in $\mathrm{LVM} / \mathrm{Ht}^{2.7}$. We suspect that the decline in circulating klotho levels reflects a loss of membrane-bound klotho from kidney tubules, as was demonstrated in a recent study by Sakan et al. [39] in patients with CKD. The loss of membrane-bound klotho should impair canonical FGF23 signaling in the kidney and CV system since klotho is the required coreceptor for FGF23/ FGF receptor (FGFR) interactions [40, 41]. However, FGF23/FGFR signaling has been demonstrated in the kidney and CV system of klotho-deficient mice [30, 37]. In a seminal paper by Faul et al. [37], FGF23/FGFR signaling stimulated LVH in a dose-responsive pattern in klotho-haploinsufficient and klotho-knockout mouse models of CKD. However, in these animal models, lower expression of klotho was accompanied by higher plasma levels of FGF23, which were not seen in our cohort. In Faul et al. [37], klotho-independent FGF23/FGFR signaling was shown to induce a hypertrophic phenotype in isolated cardiac myocytes but was not tested in other resident cells playing an important role in LVH such as fibroblasts or myofibroblasts. The mechanism of klothoindependent FGF23/FGFR signaling in CKD is unknown, but one potential explanation is the promiscuous binding of FGF23 to FGFR in cardiac myocytes that is further enhanced by reduced klotho expression in the kidney and parathyroid glands [37]. A similar paradigm has been proposed by $\mathrm{Hu}$ et al. [30], where a loss of renal klotho and an accompanying decrease in soluble klotho levels stimulated vascular calcification in animal models of CKD. Although highly speculative, our observation that the plasma FGF23/klotho ratio increased significantly over 12 months and was associated with the change in $\mathrm{LVM} / \mathrm{Ht}^{2.7}$ could reflect a similar state of klotho-independent FGF23/FGFR signaling at the level of the myocardium in stage $3 \mathrm{CKD}$. As in the animal models of CKD in Faul et al. [37], this may have contributed to progression of LVM by activating hypertrophic gene programs in cardiac myocytes.

This study has several limitations inherent to post hoc analyses, the most important of which is the small sample size that limits our ability to draw inferences about the primary outcome. We computed our achieved power for detecting a difference in $\mathrm{LVM} \mathrm{g} / \mathrm{m}^{2.7}$ from baseline to 12 months. Using the observed mean difference of $6 \mathrm{~g} / \mathrm{m}^{2.7}$ and standard deviation of $13 \mathrm{~g} / \mathrm{m}^{2.7}$ at each time point, the achieved power in our post hoc analysis was $77 \%$ with a two-tailed alpha of 0.05 . Thus, despite the small size of our cohort, we had modest power to detect the observed small but significant change in LVM g/m $\mathrm{m}^{2.7}$. Another limitation is the lack of available plasma samples to generate data in other biomarkers of progression of LVM and heart failure in patients with CKD, such as galectin-3, ST-2, troponin I, and BNP [42]. Exhaustion of the original samples precluded several subjects from inclusion in the post hoc analysis. These biomarkers should be included in future prospective studies of the progression of LVM in CKD.

In conclusion, subjects with CKD stage 3 exhibited a progressive increase in LVM with persistent LV diastolic dysfunction and vascular stiffness over 12 months despite stable kidney function, BP and normal LV systolic function. The change in FGF23/klotho ratio was associated with increasing LVM, which may reflect klotho-independent FGF23 signaling in cardiac myocytes that has been associated with $\mathrm{LVH}$ in animal models of CKD. These findings deserve further evaluation in a larger population given the adverse prognostic value of progression of these CV biomarkers.

\section{Acknowledgments}

The authors are grateful to Jingnan Mao for her assistance as a statistician. The $\mathrm{LaCO}_{3}$ and matched placebo in the original study were provided by Shire US Pharmaceuticals Inc. The study was funded by Shire US Pharmaceuticals Inc., and by NIH grants DK 070790 (K.A.H.), KL2 RR024994 and UL1 RR024992 (M.E.S. and Washington University), and L40 DK099748-01 (M.E.S.).

\section{Disclosure Statement}

K.A.H. has been a consultant for or the recipient of research funding from Shire, Genzyme and Fresenius.

References

Go AS, Chertow GM, Fan D, McCulloch CE Hsu CY: Chronic kidney disease and the risks of death, cardiovascular events, and hospitalization. N Engl J Med 2004;351:1296-1305.

$\checkmark 2$ Culleton BF, Larson MG, Wilson PW, Evans JC, Parfrey PS, Levy D: Cardiovascular disease and mortality in a community-based cohort with mild renal insufficiency. Kidney Int 1999;56:2214-2219. 
-3 Foley RN, Murray AM, Li S, Herzog CA, McBean AM, Eggers PW, Collins AJ: Chronic kidney disease and the risk for cardiovascular disease, renal replacement, and death in the United States Medicare population, 1998 to 1999. J Am Soc Nephrol 2005;16:489-495.

-4 Baber U, Gutierrez OM, Levitan EB, Warnock DG, Farkouh ME, Tonelli M, Safford MM, Muntner P: Risk for recurrent coronary heart disease and all-cause mortality among individuals with chronic kidney disease compared with diabetes mellitus, metabolic syndrome, and cigarette smokers. Am Heart J 2013;166: 373-380.e372.

5 Coresh J, Selvin E, Stevens LA, Manzi J, Kusek JW, Eggers P, Van Lente F, Levey AS: Prevalence of chronic kidney disease in the United States. J Am Med Assoc 2007;298:2038-2047.

-6 Elias MF, Davey A, Dore GA, Gillespie A, Abhayaratna WP, Robbins MA: Deterioration in renal function is associated with increased arterial stiffness. Am J Hypertens 2014;27:207214.

7 Utescu MS, Couture V, Mac-Way F, De Serres SA, Marquis K, Larivière R, Desmeules S, Lebel M, Boutouyrie P, Agharazii M: Determinants of progression of aortic stiffness in hemodialysis patients: a prospective longitudinal study. Hypertension 2013;62:154-160.

-8 Blacher J, Guerin AP, Pannier B, Marchais SJ, Safar ME, London GM: Impact of aortic stiffness on survival in end-stage renal disease. Circulation 1999;99:2434-2439.

-9 Blacher J, Guerin AP, Pannier B, Marchais SJ, London GM: Arterial calcifications, arterial stiffness, and cardiovascular risk in end-stage renal disease. Hypertension 2001;38:938-942.

10 Blacher J, Safar ME, Guerin AP, Pannier B, Marchais SJ, London GM: Aortic pulse wave velocity index and mortality in end-stage renal disease. Kidney Int 2003;63:1852-1860.

11 Foley RN, Parfrey PS, Kent GM, Harnett JD, Murray DC, Barre PE: Serial change in echocardiographic parameters and cardiac failure in end-stage renal disease. J Am Soc Nephrol 2000;11:912-916.

12 Baek SD, Baek CH, Kim JS, Kim SM, Kim JH, Kim SB: Does stage III chronic kidney disease always progress to end-stage renal disease? A ten-year follow-up study. Scand J Urol Nephrol 2012;46:232-238.

13 Van Pottelbergh G, Bartholomeeusen S, Buntinx F, Degryse J: The evolution of renal function and the incidence of end-stage renal disease in patients aged $\geq 50$ years. Nephrol Dial Transplant 2012;27:2297-2303.

- 14 Nitsch D, Grams M, Sang Y, Black C, Cirillo M, Djurdjev O, Iseki K, Jassal SK, Kimm H, Kronenberg F, Øien CM, Levey AS, Levin A, Woodward M, Hemmelgarn BR: Associations of estimated glomerular filtration rate and albuminuria with mortality and renal failure by sex: a meta-analysis. BMJ 2013; 346:f324.
15 Hallan SI, Matsushita K, Sang Y, et al: Age and association of kidney measures with mortality and end-stage renal disease. JAMA 2012;308: 2349-2360.

16 Isakova T, Xie H, Yang W, et al: Fibroblast growth factor 23 and risks of mortality and end-stage renal disease in patients with chronic kidney disease. JAMA 2011;305: 2432-2439.

17 Seifert ME, de las Fuentes L, Rothstein M, Dietzen DJ, Bierhals AJ, Cheng SC, Ross W, Windus D, Dávila-Román VG, Hruska KA: Effects of phosphate binder therapy on vascular stiffness in early-stage chronic kidney disease. Am J Nephrol 2013;38:158-167.

18 Pauca AL, O’Rourke MF, Kon ND: Prospective evaluation of a method for estimating ascending aortic pressure from the radial artery pressure waveform. Hypertension 2001;38: 932-937.

19 Van Bortel LM, Balkestein EJ, van der Heijden-Spek JJ, Vanmolkot FH, Staessen JA, Kragten JA, Vredeveld JW, Safar ME, Struijker Boudier HA, Hoeks AP: Non-invasive assessment of local arterial pulse pressure: comparison of applanation tonometry and echotracking. J Hypertens 2001;19:1037-1044.

20 O’Rourke MF, Pauca A, Jiang XJ: Pulse wave analysis. Br J Clin Pharmacol 2001;51:507-522.

21 O'Rourke MF, Adji A: An updated clinical primer on large artery mechanics: Implications of pulse waveform analysis and arterial tonometry. Curr Opin Cardiol 2005;20:275281.

22 Wilkinson IB, Fuchs SA, Jansen IM, Spratt JC, Murray GD, Cockcroft JR, Webb DJ: Reproducibility of pulse wave velocity and augmentation index measured by pulse wave analysis. J Hypertens 1998;16:2079-2084.

23 Determinants of pulse wave velocity in healthy people and in the presence of cardiovascular risk factors: 'establishing normal and reference values'. Eur Heart J Engl 2010;31: 2338-2350.

24 Lang RM, Bierig M, Devereux RB, Flachskampf FA, Foster E, Pellikka PA, Picard MH, Roman MJ, Seward J, Shanewise JS, Solomon SD, Spencer KT, Sutton MS, Stewart WJ, Chamber Quantification Writing Group; American Society of Echocardiography's Guidelines and Standards Committee; European Association of Echocardiography: Recommendations for chamber quantification: a report from the American Society of Echocardiography's Guidelines and Standards Committee and the Chamber Quantification Writing Group, developed in conjunction with the European Association of Echocardiography, a branch of the European Society of Cardiology. J Am Soc Echocardiogr 2005; 18:1440-1463.

25 de Simone G, Daniels SR, Devereux RB, Meyer RA, Roman MJ, de Divitiis O, Alderman $\mathrm{MH}$ : Left ventricular mass and body size in normotensive children and adults: assessment of allometric relations and impact of overweight. J Am Coll Cardiol 1992;20:12511260.
26 de Simone G, Devereux RB, Daniels SR, Koren MJ, Meyer RA, Laragh JH: Effect of growth on variability of left ventricular mass: assessment of allometric signals in adults and children and their capacity to predict cardiovascular risk. J Am Coll Cardiol 1995;25: 1056-1062.

27 Nagueh SF, Appleton CP, Gillebert TC, Marino $\mathrm{PN}$, Oh JK, Smiseth $\mathrm{OA}$, Waggoner $\mathrm{AD}$, Flachskampf FA, Pellikka PA, Evangelisa A: Recommendations for the evaluation of left ventricular diastolic function by echocardiography. Eur J Echocardiogr 2009;10:165-193.

28 Levey AS, Bosch JP, Lewis JB, Greene T, Rogers N, Roth D: A more accurate method to estimate glomerular filtration rate from serum creatinine: a new prediction equation. Modification of Diet in Renal Disease Study Group. Ann Int Med 1999;130:461-470.

29 Chue CD, Townend JN, Moody WE, Zehnder D, Wall NA, Harper L, Edwards NC, Steeds RP, Ferro CJ: Cardiovascular effects of sevelamer in stage 3 CKD. J Am Soc Nephrol 2013;24:842-852.

- $30 \mathrm{Hu}$ MC, Shi M, Zhang J, Quiñones H, Griffith C, Kuro-o M, Moe OW: Klotho deficiency causes vascular calcification in chronic kidney disease. J Am Soc Nephrol 2011;22:124136

$31 \mathrm{Hu}$ MC, Shi M, Zhang J, Quinones H, Kuro-o M, Moe OW: Klotho deficiency is an early biomarker of renal ischemia-reperfusion injury and its replacement is protective. Kidney Int 2010;78:1240-1251.

32 Pavik I, Jaeger P, Ebner L, Poster D, Krauer F, Kistler AD, Rentsch K, Andreisek G, Wagner CA, Devuyst O, Wüthrich RP, Schmid C, Serra AL: Soluble klotho and autosomal dominant polycystic kidney disease. Clin J Am Soc Nephrol 2012;7:248-257.

33 Moreno JA, Izquierdo MC, Sanchez-Niño MD, Suárez-Alvarez B, Lopez-Larrea C, Jakubowski A, Blanco J, Ramirez R, Selgas R, Ruiz-Ortega M, Egido J, Ortiz A, Sanz AB: The inflammatory cytokines tweak and TNFa reduce renal klotho expression through NFkB. J Am Soc Nephrol 2011;22:1315-1325.

34 Ix JH, Katz R, Peralta CA, de Boer IH, Allison MA, Bluemke DA, Siscovick DS, Lima JA, Criqui MH: A high ankle brachial index is associated with greater left ventricular mass mesa (multi-ethnic study of atherosclerosis). J Am Coll Cardiol 2010;55:342-349.

35 Peterson GE, de Backer T, Contreras G, Wang X, Kendrick C, Greene T, Appel LJ, Randall OS, Lea J, Smogorzewski M, Vagaonescu T, Phillips RA, Investigators AASoKD: Relationship of left ventricular hypertrophy and diastolic function with cardiovascular and renal outcomes in African Americans with hypertensive chronic kidney disease. Hypertension 2013;62:518-525.

36 Farshid A, Pathak R, Shadbolt B, Arnolda L, Talaulikar G: Diastolic function is a strong predictor of mortality in patients with chronic kidney disease. BMC Nephrol 2013;14:280. 
37 Faul C, Amaral AP, Oskouei B, Hu MC, et al: FGF23 induces left ventricular hypertrophy. J Clin Invest 2011;121:4393-4408.

38 Gutiérrez OM, Januzzi JL, Isakova T, Laliberte K, Smith K, Collerone G, Sarwar A, Hoffmann U, Coglianese E, Christenson R, Wang TJ, deFilippi C, Wolf M: Fibroblast growth factor 23 and left ventricular hypertrophy in chronic kidney disease. Circulation 2009;119:2545-2552.
Sakan H, Nakatani K, Asai O, Imura A, Tanaka T, Yoshimoto S, Iwamoto N, Kurumatani N, Iwano M, Nabeshima Y, Konishi N, Saito $\mathrm{Y}$ : Reduced renal $\alpha$-klotho expression in CKD patients and its effect on renal phosphate handling and vitamin D metabolism. PLoS One 2014;9:e86301.

40 Goetz R, Beenken A, Ibrahimi OA, Kalinina J, Olsen SK, Eliseenkova AV, Xu C, Neubert TA, Zhang F, Linhardt RJ, Yu X, White KE, Inagaki T, Kliewer SA, Yamamoto M, Kurosu H, Ogawa Y, Kuro-o M, Lanske B, Razzaque MS, Mohammadi M: Molecular insights into the klotho-dependent, endocrine mode of action of fibroblast growth factor 19 subfamily members. Mol Cell Biol 2007;27:3417-3428.
41 Kurosu H, Ogawa Y, Miyoshi M, Yamamoto M, Nandi A, Rosenblatt KP, Baum MG, Schiavi S, Hu MC, Moe OW, Kuro-o M: Regulation of fibroblast growth factor-23 signaling by klotho. J Biol Chem 2006;281:61206123.

42 Tang WH, Shrestha K, Shao Z, Borowski AG, Troughton RW, Thomas JD, Klein AL: Usefulness of plasma galectin-3 levels in systolic heart failure to predict renal insufficiency and survival. Am J Cardiol 2011;108:385-390. 